\title{
DENTAL HYGIENE AND FLUORIDATION OF WATER
}

$\mathrm{N}$ WARLY fifty years ago two Amorican dentists directed attention to a condition of the toeth, characterized by unsightly mottling of the enamel, which occurred in the inhabitants of certain wolldefined arcas. The cause of this abnormality was lator shown to be tho presence of fluoride in the drinking water, the topographical distribution of cases being duo to variations in naturally occurring fluorides in the water in different localities. Lesions occurred only in persons who had beon exposed as children to fluoride-containing water and did not occur in adults who had passed their childhood olsewhere. The proportion of persons affoctod, and the oxtont of the lesions, wero shown to vary directly with the concentration of fluoride in the wator. Later, it was found that though the enomel could be so soverely affected that the tooth appeared to be quite badly damaged, they were at the same time much less susceptiblo to dental caries than were normal tcoth. These findings were confirmed in many subsequent investigations, and it has now been established that concontrations of fluorine salts of more than 1.0 part per million in drinking water may lead to the appearance of onamol lesions and also to increased resistance to caries. At this level, howover, the losions are minimal and very fow persons are affected. With increasing concentrations the lesions become more pronounced and more membors of the population show them. Nevertheless, the resistance to caries which was found to be associated with the presence of very obvious lesions is still present when the level of fluorides in the drinking water is so small that only very occasional lesions of minimal proportions occur in a few peoplo. Investigations in the United States havo shown that the degree of this resistance is such that children born and brought up in aroas with 1.0 p.p.m. of fluorido occurring naturally in the water have up to 60 per cent less dental carios than children brought up in aroas where there is only a trace of fluoride in the water.

Further investigations in tho United States and Canada showed that the addition of fluoride to water sufficient to raise the fluoride content to 1.0 p.p.m. had the same effect on the incidence of dental caries as water with naturally occurring fluoride. As a rosult of these findings, a British mission to the United States and Canade in 1952 recommended that fluorido should be added to the water supplios of selected communities in tho United Kingdom, as a pilot study. Tho Ministry of Hcalth report, The Conduct of the Fluoridation Studies in the United Kingdom and the Results Achieved after Five Years*, now gives the results of these investigations carried out in Watford, in part of Anglosey and in Kilmarnock. Andover was originally designatod as a fourth study aroa; but fluoridation was discontinued by the local authority after two years.

The report gives details of the carefully controlled investigations which have now been in progress for five years. Only the findings for the deciduous teeth of children aged 3-7 yoars aro given, since tho full effect of fluoride is only exerted when it is absorbed continuously during the whole poriod of tooth forma. tion and calcification. The data show that whoreas prior to fluoridation in 1955-56 childron aged three years had on average 3.80 carious teeth, the figure for this age in 1961 was 1.29. The corrosponding figures for four-year-old children wore $5 \cdot 39$ and $2 \cdot 31$, and for five-year-old children $5 \cdot 81$ and $2 \cdot 91$. These figures represent reductions of carios incidence of 66 por cent, 57 por cent and 50 por cent respectivoly. There was also a reduction of incidence of caries in the control areas, but only in the region of betweon 2 and 7 por cent. In children of six and soven years, some of whose teoth were already calcified before fluoridation commenced, the reduction of caries was of a lesser degree.

In addition to these striking figuros, tho roport deals with the question of the safoty of fluoridation and also gives some details of tho technical problems involved in the fluoridation of public water supplies. With rogard to possible toxicity, tho fullest investigation of all available evidence has been made and it is concluded that no harm results from raising tho fluoride content of drinking water to 1.0 p.p.m. This agrees with the opinion of the World Health Organiza. tion's Export Committee which, after examining the evidence, concluded that: "All these findings fit together in a consonant whole that constitutes a great guarantee of safety - a body of evidence with. out precedent in public health proceduros".

This century has witnessed many triumphs of preventive and curative medicine. It is clear that this short report embodies yet another. R. B. Lucas

* Ministry of Health: Scottish Office; Ministry of Housing and Local Government. Reports on Public Health and Medical Subjects No. 105: The Conduct of the Fluoridation Studies in the United Ringdom and the results achieved after five years. $\mathrm{P}_{\mathrm{F}} \mathrm{li1}+60$. (London: H.M. Stationery Offce, 1962.) 4s. net.

\section{ICARUS}

\begin{abstract}
NEW journal, entitled Icarus, has recently been A publishod*. It is yot another of those interded to servo a part of that enormous new field of sciontific activity popularly known as 'space resoarch'. According to the editors it is to deal with "the new inter-

- Icarus, Vol. 1 No. 1 (May 1962). International Journal of the Solar system. Edited by Z. Kopal and A. G. Wilson. Pp. 93. Subseription rates (Vol. 1, 6 issucs): Institutional subscribers, 18 dollars Private subscribers certifying that the journal is for personal use, 10 dollars. (New York and London: Acadcmic Press, Inc.,
146e.)
\end{abstract}

disciplinary suience of tho solar system-which is emerging to claim its own identity at the cross-roads of the allied disciplines of astronomy, goology, geophysics, meteorology, geochomistry, plasma physics, and biology". "Thoir aim is "to make a positive contribution to the cause of scientifie communication in three distinct ways:

" $(a)$ by a selective concentration of subjects which would otherwise have appoared in a variety of widoly scattorod sciontific pariodicals to establish a large- 
signal, low-noise channel for information on most scientific aspects of the solar system;

" $(b)$ by minimizing delay between the receipt of a communication and its publication to effect the promptness of communication essential in a so rapidly developing field of science;

" $(c)$ by inclusion of a bibliographical section covering all fields of interest to investigators of the solar system to ease the task of monitoring the information".

There are 35 associate editors, most of whose names are already well known. Their function is to collect papers and also to act as referees. It remains to be seen whether this arrangement will prove more successful than that of anonymous referees, whom we all find reasonably efficiont in dealing with the papers of other authors, although so tiresome with our own.

Fantastically great resources are at present being devoted to space research; but most of the effort is still being channelled into elaborate and lengthy preparations for difficult experiments, of which comparatively fow have yet had time to produce results. If all goes according to plan, ultimately, the amount of now material to be published and discussed may be very great. But so far, relative to the scale of the effort, the volume of results to reach the stage of publication is small (although this is not to minimize their significance). Clearly, Icarus has been started in the expectation of taking part in the harvest; but in common with other similar journals it must, for the present, rely chiefly on papers that could equally well have appeared in one or other of half a dozen existing periodicals. This at least seems true of Icarus, 1 , No. 1. It contains a long paper by A. G. W. Cameron discussing the problem of the formation of the Sun and planets, and three much shorter papers on the interplanetary medium, on the behaviour of photoelectrons emitted by solid bodies such as the Moon, and about the blue haze on Mars. There is also a letter discussing toroidal oscillations of the Moon.

Science is to-day more than ever in danger of sharing the fate of the Tower of Babel. However, the editors of Icarus believe that continued progress can be ensured by the formation of fresh, specialized sub-groups, each drawn from a fairly wide field of existing studies and provided with its own specialized journals. This kind of approach is not exactly new; it has been fruitful in the past and perhaps it promises better than any other. We are in a period of excessively rapid change in astronomy and in every other science connected with space research, affecting theories, instrumentation, administration, and ideas of all kinds, so that it is very difficult to say with confidence what policies are wisest. But so far as publications are concerned, I question whether existing journals are so overloaded that they cannot absorb comfortably all the papers on astronomy likely to result from space research for at least two or three years yet. By then we may be able to see the needs of the situation more clearly.

The financial problems of existing journals are not negligible, and the extra support of space researeh papers, should it lead to a greater circulation, as it probably would, might in most cases be very welcome. Further, I think it important that space research workers should know what is going on in the older astronomy, and that equally the older kind of astronomer should get to know about space research. Ton or fifteen years ago, after some initial fumbling, radio and optical astronomers discovered that they were better off together than apart, and now to a large extent publish their papers together in the same journals. I hope that this kind of development will come about in the case of astronomy conducted with rockets, artificial satellites, otc.

As to rapidity of publication, the average interval between receipt of manuscript and publication is slightly greater in Icarus, 1, No. 1, than in Monthly Notices of the Royal Astronomical Society, 124, No. 1, also dated May 1962, a journal now 135 years old, which still manages to cover most of astronomy at a satisfactory level of originality and technical quality.

The bibliography mentioned by the editors include 349 papers in this issue, the great majority from astronomical journals. They are classified, but no abstracts are given. Policy for this section of Icarus is still fluid, and one must wait for further issues before being able to judge whether there will be a distinctive service not yet provided by existing abstracting journals.

\section{R. O. Redman}

\section{PLANNING NEW COMMUNITIES IN BRITAIN}

\begin{abstract}
WHE report of the Carnegie United Kingdom Trust for 1960 gave some account of the study of the social problems of new communities in Britain which Dr. J. H. Nicholson had made at the request of the Trust and of the National Council for Social Service, and stated also that the Trust had set aside $£ 100,000$ in the new quinquennium, which opened in 1961, in order to promote pioneer projects in the provision of social amenities in new communities. The Trust has also appointed an Advisory Committee to consider applications, and where appropriate, to initiate action. Up to the end of 1961 no project, however, had been brought to the point of qualifying for a grant from this fund, practically all failing to measure up to the required standard of innovation. The fund is reserved for assisting work that is now on a national scale, and the Trust is prepared to wait for the right projects.
\end{abstract}

It is hoped that by the end of 1962 a pattern of expenditure will be planned which will provide assistance for promising projects in one or more of each type of new community in different geographical regions.

Dr. Nicholson's report was published in August $1961 *$, and the importance attached by the Carnegie United Kingdom Trust to this work is well indicated by the fact that in its report for $1961 \uparrow$ the Trust includes Dr. Nicholson's general recommendations in extenso as well as those on social development. His report is concerned with the now communities

* Nero Communities in Britain: Achievements and Problems. By J. H. Nicholson. Pp. 191. (London: The National Council of Social J. H. Nicholson. Pp. 191. (L

† The Carnegie United Kingdom Trust. 48th Annual Report, 1961. Pp. viii +76 . (Dunfermline, Fife: The Carnegie United Kingdom Trust, 1962.) (See also Nature, 195, 338; 1982.) 